\title{
Association of glycemic variability with left ventricular diastolic function in type 2 diabetes mellitus
}

\author{
Shun Yokota ${ }^{1}$, Hidekazu Tanaka ${ }^{1 *}$, Yasuhide Mochizuki ${ }^{1}$, Fumitaka Soga' ${ }^{1}$ Kentaro Yamashita', \\ Yusuke Tanaka', Ayu Shono ${ }^{1}$, Makiko Suzuki ${ }^{1}$, Keiko Sumimoto $^{1}$, Jun Mukai ${ }^{1}$, Makiko Suto ${ }^{1}$, Hiroki Takada ${ }^{1}$, \\ Kensuke Matsumoto ${ }^{1}$, Yushi Hirota ${ }^{2}$, Wataru Ogawa ${ }^{2}$ and Ken-ichi Hirata ${ }^{1}$
}

\begin{abstract}
Background: Type 2 diabetes mellitus (T2DM) is a major cause of heart failure (HF) with preserved ejection fraction (HFpEF), usually presenting as left ventricular (LV) diastolic dysfunction. Thus, LV diastolic function should be considered a crucial marker of a preclinical form of DM-related cardiac dysfunction. However, the impact of glycemic variability (GV) on LV diastolic function in such patients remains unclear.

Methods: We studied 100 asymptomatic T2DM patients with preserved LV ejection fraction (LVEF) without coronary artery disease (age: $60 \pm 14$ years, female: $45 \%$ ). GV was evaluated as standard deviation of blood glucose level using continuous glucose monitoring system for at least 72 consecutive hours. LV diastolic function was defined as mitral inflow $E$ and mitral $e^{\prime}$ annular velocities ( $\left.E / e^{\prime}\right)$, and $>14$ was determined as abnormal.

Results: E/e' in patients with high GV ( $\geq 35.9 \mathrm{mg} / \mathrm{dL}$ ) was significantly higher than that in patients with low GV $(11.3 \pm 3.9$ vs. $9.8 \pm 2.8, p=0.03)$ despite similar age, gender-distribution, and hemoglobin A1c (HbA1c). Multivariate logistic regression analysis showed that GV $\geq 35.9$ mg/dL (odds ratio: 3.67; 95\% confidence interval: 1.02-13.22; $p<0.05$ ) was an independently associated factor, as was age, of E/e'> 14. In sequential logistic models for the associations of LV diastolic dysfunction, one model based on clinical variables including age, gender and hypertension was not improved by addition of HbA1c $(p=0.67)$ but was improved by addition of high GV $(p=0.04)$.
\end{abstract}

Conclusion: Since HFpEF is a syndrome caused by diverse agents, reducing GV may represent a potential new therapeutic strategy for the prevention of the development of HFpEF in T2DM patients.

Keywords: Type 2 diabetes mellitus, Glycemic variability, Diastolic function, Echocardiography

\section{Background}

Type 2 diabetes mellitus (T2DM), as well as cardiovascular disease, is a major cause of heart failure (HF), both with reduced ejection fraction (HFrEF) and with preserved ejection fraction (HFpEF), $[1,2]$. HF as well as T2DM is therefore one of the most worrying global public health problems [3]. Several studies have

\footnotetext{
*Correspondence: tanakah@med.kobe-u.ac.jp

${ }^{1}$ Division of Cardiovascular Medicine, Department of Internal Medicine, Kobe University Graduate School of Medicine, 7-5-2, Kusunoki-cho,

Chuo-ku, Kobe 650-0017, Japan

Full list of author information is available at the end of the article
}

demonstrated that T2DM significantly increases the risk of recurrent HF hospitalizations and the duration of hospital stay for HF patients. The presence of T2DM is also associated with a significantly higher mortality than its absence [4]. Moreover, suboptimal glycemic control and impaired insulin sensitivity characteristic of T2DM have also been found to be directly correlated with an increased risk of developing HF $[5,6]$. T2DM is also a major cause of HFpEF, while LV diastolic function was found to be strongly associated with $\operatorname{HFpEF}[7,8]$. It is well known that patients with HF face a risk of similar magnitude regardless of their EF status because there is currently no effective pharmacological therapy for 
patients with HFpEF. Interest has therefore been growing in a reliable therapy for HFpEF or in improvement of LV diastolic function for T2DM patients with preserved LVEF since these may lead to more effective prevention of the development of HFpEF in such patients. On the other hand, glycemic variability (GV) has specific clinical implications, as well as a different significance than that of classical markers such as hemoglobin A1c (HbA1c) [9]. A continuous glucose monitoring system (CGM) is an emerging technology that can continuously measure glucose levels, thereby enabling evaluation of GV. It has been widely known that GV is strongly associated with the progression of coronary artery disease in T2DM patients [10]. However, it remains uncertain if GV represent a potential new therapeutic strategy for the prevention of the development of HFpEF in asymptomatic T2DM patients with preserved LVEF. The objective of this study was, therefore, to investigate the impact of GV on the LV diastolic function of such patients.

\section{Methods}

A total of $100 \mathrm{DM}$ patients were retrospectively enrolled in this study. They had been admitted to Kobe University Hospital between July 2013 and September 2015 and undergone both echocardiography and CGM. Preliminary exclusion criteria for this study were: (1) history of coronary artery disease; (2) LVEF $<50 \%$; (3) previous history of open-heart surgery or congenital heart disease; (4) severe renal dysfunction defined as glomerular filtration rate $<30 \mathrm{~mL} / \mathrm{min} / 1.73 \mathrm{~m}^{2}$; (5) uncontrolled hypertension >180/100 mmHg; (6) more than moderate valvular heart disease; and (7) atrial fibrillation. All enrolled patients underwent an exercise stress screening test such as a treadmill exercise or stress myocardial perfusion scintigraphy during their hospitalization, and patients with an ischemic response were excluded. The diagnosis of T2DM was based on the World Health Organization criteria [11]. This study was approved by the local ethics committee of our institution (No. 180332).

\section{Echocardiographic examination}

All echocardiographic data were obtained by means of a commercially available echocardiographic system (Vivid E9; GE-Vingmed, Horten, Norway) within 2 weeks after admission. Digital routine grayscale two-dimensional cine loops from three consecutive heart beats were obtained at end-expiratory apnea from standard parasternal and apical views. Sector width was optimized to allow for complete myocardia visualization while maximizing the frame rate. Standard echocardiographic measurements were obtained according to the current guidelines of the American Society of Echocardiography (ASE)/European Association of Cardiovascular Imaging
(EACVI) [12]. Specifically, the early diastolic (E) and atrial wave (A) velocities and the E-wave deceleration time were measured by means of pulsed wave Doppler recording from the apical four-chamber view. Spectral pulsed-wave Doppler-derived early diastolic velocity $\left(\mathrm{e}^{\prime}\right)$ was obtained by averaging the septal and lateral mitral annulus, and the $\mathrm{E} / \mathrm{e}^{\prime}$ ratio was then calculated to obtain an estimate of LV filling pressure. In particular, E/e' $>14$ was evaluated as LV diastolic dysfunction as recommended by the ASE/EACVI [13].

\section{Assessment of GV by means of CGM}

Less than 6 days of echocardiographic examination, all patients underwent CGM at least $72 \mathrm{~h}$ which continuously measured blood glucose level every $5 \mathrm{~min}$ by means of a commercially available CGM system (iPro2, Medtronic, Northridge, CA). GV was evaluated as standard deviation (SD) of blood glucose level. The patients were then divided into two groups based on the average SD of blood glucose levels $(35.9 \mathrm{mg} / \mathrm{dL})$.

\section{Statistical analysis}

Continuous variables were expressed as mean values with SD for normally distributed data and as medians values with interquartile range for non-normally distributed data. Categorical variables were expressed as frequencies and percentages. The parameters of the two subgroups were compared by using Student $t$ test or Mann-Whitney $U$ test as appropriate. Proportional differences were evaluated with Fisher's exact test. The initial univariate logistic regression analysis to identify univariate determinants of LV diastolic dysfunction $\left(E / \mathrm{e}^{\prime}>14\right)$ was followed by a multivariate logistic regression model using stepwise selection, with the p levels for entry from the model set at $<0.10$. Sequential logistic models were performed to determine the incremental benefit of $\mathrm{GV}$ in relation to clinical variables including age, gender, hypertension, and HbA1c. A statistically significant increase in the global $\log$-likelihood $\chi^{2}$ of the model was defined as representing an incremental predictive value. For all steps, a $\mathrm{p}$ value of $<0.05$ was considered statistically significant. All analyses were performed with commercially available software (MedCalc software version 19.0.7.; MedCalc Software, Mariakerke, Belgium).

\section{Results}

\section{Comparison between clinical and echocardiographic characteristics of high and low GV groups}

The baseline clinical and echocardiographic characteristics of the 100 T2DM patients are summarized in Table 1. Their mean age was $60 \pm 14$ years, LVEF was $65.6 \pm 4.9 \%$, and 45 patients (45\%) were female. The high GV group comprised 43 T2DM patients (43\%) with an average SD 
Table 1 Baseline characteristics of patients

\begin{tabular}{|c|c|}
\hline Variables & All patients $(n=100)$ \\
\hline \multicolumn{2}{|l|}{ Clinical characteristics } \\
\hline Age, years & $60 \pm 14$ \\
\hline Gender (female), n (\%) & $45(45)$ \\
\hline DM duration, years & $10(0.1-42)$ \\
\hline Body weight, kg & $67 \pm 16$ \\
\hline $\mathrm{BSA}, \mathrm{m}^{2}$ & $1.70 \pm 0.22$ \\
\hline Systolic blood pressure, mmHg & $129 \pm 19$ \\
\hline Heart rate, bpm & $74 \pm 10$ \\
\hline BUN, mg/dL & $15.6 \pm 5.7$ \\
\hline Creatinine, mg/dL & $0.86 \pm 0.43$ \\
\hline $\mathrm{eGFR}, \mathrm{mL} / \mathrm{min} / 1.73 \mathrm{~m}^{2}$ & $73.4 \pm 25.4$ \\
\hline $\mathrm{HbA1c}, \%$ & $8.5 \pm 1.9$ \\
\hline \multicolumn{2}{|l|}{ Comorbidities, n (\%) } \\
\hline Hypertension & $58(58)$ \\
\hline Dyslipidemia & $63(63)$ \\
\hline \multicolumn{2}{|l|}{ Anti-hypertensive drugs, n (\%) } \\
\hline Calcium channel blockers & $38(38)$ \\
\hline ACE inhibitor/ARB & $54(54)$ \\
\hline Mineralocorticoid receptor antagonist & $1(1)$ \\
\hline \multicolumn{2}{|l|}{ Anti-diabetic drugs, n (\%) } \\
\hline DPP-4 inhibitor & $51(51)$ \\
\hline GLP-1 RA & $11(11)$ \\
\hline SU & $28(28)$ \\
\hline$a-G l$ & $23(23)$ \\
\hline Thiazalidine & $8(8)$ \\
\hline Metformin & $57(57)$ \\
\hline SGLT2 inhibitor & $3(3)$ \\
\hline \multicolumn{2}{|l|}{ Echocardiographic parameters } \\
\hline LV end-diastolic volume, mL & $76.0 \pm 22.0$ \\
\hline LV end-systolic volume, mL & $26.8 \pm 10.7$ \\
\hline LVEF, \% & $65.6 \pm 4.9$ \\
\hline LVMI, g/m² & $80.0 \pm 19.0$ \\
\hline $\mathrm{LAVI}, \mathrm{mL} / \mathrm{m}^{2}$ & $30.1 \pm 8.0$ \\
\hline $\mathrm{e}^{\prime} \mathrm{cm} / \mathrm{s}$ & $6.05 \pm 1.67$ \\
\hline$E / e^{\prime}$ & $10.5 \pm 3.4$ \\
\hline \multicolumn{2}{|l|}{ Trans-mitral flow } \\
\hline $\mathrm{E}, \mathrm{cm} / \mathrm{s}$ & $59.4 \pm 13.7$ \\
\hline Dct, msec & $207 \pm 53$ \\
\hline$E / A$ & $0.8 \pm 0.2$ \\
\hline \multicolumn{2}{|l|}{ Pulmonary venous flow } \\
\hline $\mathrm{S}, \mathrm{cm} / \mathrm{s}$ & $65.4 \pm 16.1$ \\
\hline $\mathrm{D}, \mathrm{cm} / \mathrm{s}$ & $41.3 \pm 8.0$ \\
\hline$S / D$ & $1.6 \pm 0.4$ \\
\hline $\mathrm{A}, \mathrm{cm} / \mathrm{s}$ & $38.2 \pm 20.0$ \\
\hline
\end{tabular}

Values are mean \pm SD for normally distributed data and median and interquartile range for non-normally distributed data, or $n$ (\%). Assessment of pulmonary venous flow was available in 90 patients

$D M$ diabetes mellitus, BSA body surface area, $B U N$ blood urea nitrogen, $e G F R$ estimated glomerular filtration rate, $A C E$ angiotensin-converting enzyme, $A R B$ angiotensin II receptor blocker, DPP-4 Dipeptidyl Peptidase-4, GLP-1 RA glucagon-like peptide-1 receptors agonists, SU Sulfonylureas, $a$-Gl a-glucosidase inhibitors, SGLT2 Sodium glucose cotransporter type 2, LVEF left ventricular

\section{Table 1 (continued)}

ejection fraction, LVMI left ventricular mass index, LAVI left atrial volume index, e'spectral pulsed-wave Doppler-derived early diastolic velocity from the septal mitral annulus, E peak early diastolic mitral flow velocity, DcT E wave deceleration time, E/A peak early and late diastolic mitral flow velocity ratio, $S$ peak systolic velocity of pulmonary venous flow, D peak diastolic velocity of pulmonary venous flow, A peak velocity of pulmonary venous flow during atrial systole

for blood glucose level of $\geq 35.9 \mathrm{mg} / \mathrm{dL}$ and the remaining 57 (57\%) were classified as the low GV group. The clinical and echocardiographic characteristics of the high and low GV groups are summarized in Table 2. Most of the clinical and echocardiographic characteristics were similar, but one important difference was that $\mathrm{E} / \mathrm{e}^{\prime}$ of the high GV group was significantly higher than that of the low GV group (11.3 \pm 3.9 vs. $9.8 \pm 2.8, \mathrm{p}=0.03$; Fig. 1$)$.

\section{Association of GV with LV diastolic function}

Table 3 shows the results of the univariate and multivariate logistic regression analyses for the association of GV with LV diastolic dysfunction, defined as E/e'>14 for T2DM patients. An important finding of the multivariate regression analysis was that high GV, defined as an average SD for blood glucose level of $\geq 35.9 \mathrm{mg} / \mathrm{dL}$, was an independent determinant parameter, as was age, for LV diastolic dysfunction (OR 3.670; 95\% CI 1.019-13.220; $p=0.047$ ). Furthermore, the incremental benefits determined by means of sequential logistic models of the association of LV diastolic dysfunction are shown in Fig. 2. One model, based on clinical variables including age, gender and hypertension $\left(x^{2}=11.6\right)$, showed no improvement for the addition of HbA1c $\left(x^{2}=11.8, p=0.67\right)$, but did show improvement for the addition of high GV $\left(x^{2}=16.0, p=0.04\right)$.

Next, all patients were divided into two groups based on the median value of HbA1c $(8.2 \mathrm{mg} / \mathrm{dL})$. E/e' for the high $(\geq 8.2 \mathrm{mg} / \mathrm{dL})$ and low $(<8.2 \mathrm{mg} / \mathrm{dL}) \mathrm{HbA1c}$ groups was similar (10.2 \pm 3.2 vs. $10.7 \pm 3.5$, p =0.46; Fig. 3a), but that for patients with high GV in the low HbA1c group was significantly higher than that for patients with low GV in the high HbA1c group (11.9 \pm 4.3 vs. 9.6 \pm 3.0 , $\mathrm{p}=0.04$; Fig. 3b).

\section{Discussion}

The findings of our study indicate that LV diastolic function in the high GV group of asymptomatic T2DM patients with preserved LVEF was significantly worse than that in the low GV patient group. In addition, high GV was independently associated with LV diastolic dysfunction, and also added significantly to the predictive value of LV diastolic dysfunction. 
Table 2 Comparison of variables between high and low GV groups

\begin{tabular}{|c|c|c|c|}
\hline \multirow{2}{*}{$\begin{array}{l}\text { Variables } \\
\text { Clinical characteristics }\end{array}$} & \multirow[t]{2}{*}{$\begin{array}{l}\text { High GV } \\
\text { group }(n=43)\end{array}$} & \multicolumn{2}{|c|}{$\begin{array}{l}\text { Low GV groupp value } \\
(n=57)\end{array}$} \\
\hline & & & \\
\hline Age, years & $61.2 \pm 15.0$ & $59.4 \pm 13.1$ & 0.53 \\
\hline Gender (female), n (\%) & $19(44)$ & $26(46)$ & 0.89 \\
\hline DM duration, years & $12(0.5-42)$ & $8(0.1-34)$ & 0.04 \\
\hline Body weight, kg & $63.7 \pm 13.4$ & $69.6 \pm 17.0$ & 0.07 \\
\hline$B S A, m^{2}$ & $1.67 \pm 0.19$ & $1.73 \pm 0.24$ & 0.15 \\
\hline Systolic blood pressure, $\mathrm{mmHg}$ & $131 \pm 21$ & $128 \pm 17$ & 0.44 \\
\hline Heart rate, bpm & $72 \pm 10$ & $76 \pm 10$ & 0.05 \\
\hline BUN, mg/dL & $16.5 \pm 5.8$ & $15.0 \pm 5.6$ & 0.20 \\
\hline Creatinine, mg/dL & $0.93 \pm 0.45$ & $0.80 \pm 0.40$ & 0.13 \\
\hline $\mathrm{eGFR}, \mathrm{mL} / \mathrm{min} / 1.73 \mathrm{~m}^{2}$ & $66.2 \pm 22.8$ & $78.8 \pm 25.9$ & 0.01 \\
\hline $\mathrm{HbA} 1 \mathrm{c}, \%$ & $8.7 \pm 1.9$ & $8.3 \pm 2.0$ & 0.23 \\
\hline \multicolumn{4}{|l|}{ Comorbidities, n (\%) } \\
\hline Hypertension & $26(60)$ & $32(56)$ & 0.67 \\
\hline Dyslipidemia & $25(58)$ & $38(67)$ & 0.39 \\
\hline \multicolumn{4}{|l|}{ Anti-hypertensive drugs, n (\%) } \\
\hline Calcium channel blockers & $22(37)$ & $16(39)$ & 0.89 \\
\hline ACE inhibitor/ARB & $32(56)$ & $22(51)$ & 0.63 \\
\hline $\begin{array}{l}\text { Mineralocorticoid receptor } \\
\text { antagonist }\end{array}$ & $1(2)$ & $0(0)$ & 0.25 \\
\hline \multicolumn{4}{|l|}{ Anti-diabetic drugs, n (\%) } \\
\hline DPP-4 inhibitor & $20(47)$ & $31(54)$ & 0.44 \\
\hline GLP-1 RA & $3(7)$ & $8(14)$ & 0.27 \\
\hline SU & $15(35)$ & $12(23)$ & 0.19 \\
\hline $\mathrm{a}-\mathrm{Gl}$ & $10(23)$ & $13(23)$ & 0.96 \\
\hline Thiazalidine & $2(5)$ & $6(11)$ & 0.29 \\
\hline Metformin & $18(42)$ & $39(68)$ & 0.007 \\
\hline SGLT2 inhibitor & $0(0)$ & $3(5)$ & 0.13 \\
\hline \multicolumn{4}{|l|}{ Echocardiographic parameters } \\
\hline LV end-diastolic volume, mL & $76.1 \pm 23.4$ & $75.9 \pm 20.9$ & 0.97 \\
\hline LV end-systolic volume, mL & $25.9 \pm 11.3$ & $27.5 \pm 10.2$ & 0.48 \\
\hline LVEF, \% & $66.8 \pm 5.4$ & $64.8 \pm 4.3$ & 0.04 \\
\hline LVMI, g/m² & $81.7 \pm 19.4$ & $78.5 \pm 18.5$ & 0.41 \\
\hline $\mathrm{LAVI}, \mathrm{mL} / \mathrm{m}^{2}$ & $31.4 \pm 8.8$ & $29.2 \pm 7.1$ & 0.17 \\
\hline $\mathrm{e}^{\prime}, \mathrm{cm} / \mathrm{s}$ & $5.9 \pm 1.8$ & $6.2 \pm 1.5$ & 0.44 \\
\hline$E / e^{\prime}$ & $11.3 \pm 3.9$ & $9.8 \pm 2.8$ & 0.03 \\
\hline \multicolumn{4}{|l|}{ Trans-mitral flow } \\
\hline $\mathrm{E}, \mathrm{cm} / \mathrm{s}$ & $61.1 \pm 12.8$ & $58.1 \pm 14.2$ & 0.28 \\
\hline Dct, msec & $210 \pm 49$ & $205 \pm 55$ & 0.59 \\
\hline E/A & $0.8 \pm 0.2$ & $0.8 \pm 0.3$ & 0.75 \\
\hline \multicolumn{4}{|l|}{ Pulmonary venous flow } \\
\hline $\mathrm{S}, \mathrm{cm} / \mathrm{s}$ & $67.2 \pm 16.8$ & $64.0 \pm 15.3$ & 0.36 \\
\hline $\mathrm{D}, \mathrm{cm} / \mathrm{s}$ & $43.3 \pm 8.4$ & $40.0 \pm 7.3$ & 0.04 \\
\hline$S / D$ & $1.6 \pm 0.4$ & $1.6 \pm 0.7$ & 0.65 \\
\hline $\mathrm{A}, \mathrm{cm} / \mathrm{s}$ & $42.5 \pm 24.9$ & $34.8 \pm 13.8$ & 0.07 \\
\hline
\end{tabular}

Values are mean \pm SD for normally distributed data and median and interquartile range for non-normally distributed data, or $\mathrm{n}(\%)$

Assessment of pulmonary venous flow was available in 40 patients (High GV group) and 50 patients (Low GV group)

GV glycemic viability

All other abbreviation as in Table 1

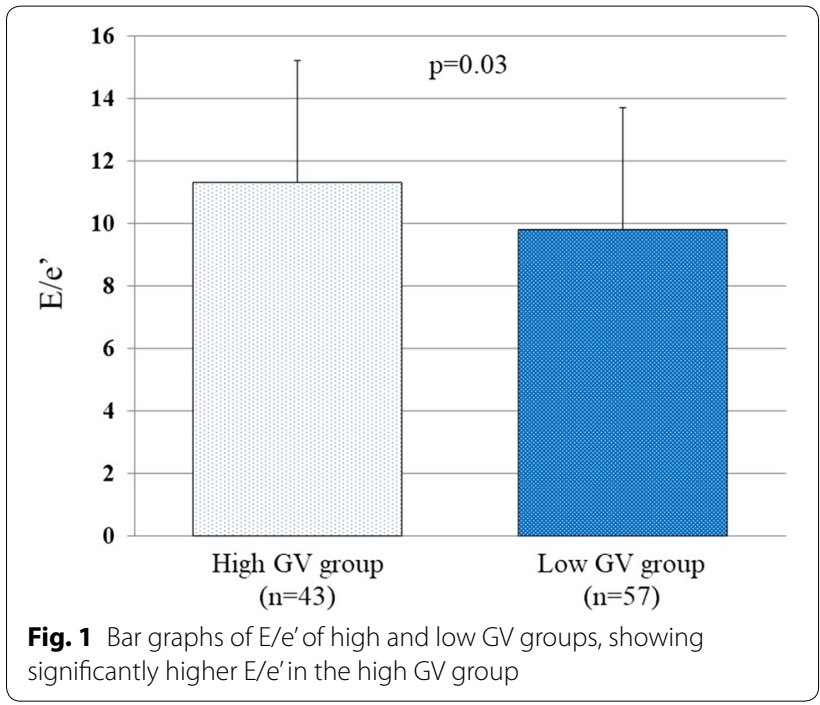

Importance of GV in T2DM

Both HF and DM strongly influence each other, with the onset of one portending a worse prognosis and further disease progression for the other. The Framingham Study reported a twofold increase in frequency of HF for men with DM and a fivefold increase for women with DM, independent of coronary artery disease and hypertension [14]. This relationship between DM and $\mathrm{HF}$ is the result of structural, metabolic, and functional impairment. Hyperglycemia may cause structural alterations, including microvascular remodeling and cardiac fibrosis, a finding hypothesized to be secondary to the accumulation of advanced glycation end products [15]. Thus, suboptimal glycemic control in DM and impaired insulin sensitivity have been directly correlated with an increased risk of developing HF [5, 6]. Moreover, higher HbA1c in HF patients has been associated with increased mortality $[16,17]$, but other studies have found a paradoxical or J-shaped relationship between HbA1c and outcomes, indicating that hypoglycemia may mitigate the possible benefits of lower HbA1c $[18,19]$. CGM, on the other hand, reportedly has the potential to uncover patterns in glucose control which are not captured by HbA1c, and GV has specific clinical implications, as well as different significance from those of classical markers such as HbA1c [9], and is also strongly associated with the progression of coronary artery disease in T2DM patients [10]. Furthermore, GV was found to be independently related to carotid intima-media thickness and may contribute to the development of atherosclerosis in individuals with diabetes independent of other risk factors $[20$, 21]. Other findings showed GV to be a specific trigger for oxidative stress [22], which reportedly promotes 
Table 3 Associated factor of LV diastolic dysfunction

\begin{tabular}{|c|c|c|c|c|c|c|}
\hline & \multicolumn{3}{|c|}{ Univariate } & \multicolumn{3}{|c|}{ Multivariate } \\
\hline & OR & $95 \% \mathrm{Cl}$ & p value & OR & $95 \% \mathrm{Cl}$ & $p$ value \\
\hline Age & 1.077 & $1.017-1.141$ & 0.011 & 1.070 & $1.012-1.131$ & 0.017 \\
\hline Female & 2.500 & $0.773-8.089$ & 0.126 & & & \\
\hline Body surface area & 0.076 & $0.004-1.293$ & 0.075 & & & \\
\hline Hypertension & 5.217 & $1.101-24.724$ & 0.037 & & & \\
\hline Dyslipidemia & 1.067 & $0.329-3.462$ & 0.914 & & & \\
\hline $\mathrm{HbA} 1 \mathrm{c}$ & 1.042 & $0.788-1.378$ & 0.774 & & & \\
\hline High GV & 4.015 & $1.164-13.852$ & 0.028 & 3.670 & $1.019-13.220$ & 0.047 \\
\hline LVEF & 1.176 & $1.018-1.385$ & 0.774 & & & \\
\hline LVMI & 1.027 & $0.998-1.057$ & 0.074 & & & \\
\hline LAVI & 1.06 & 0.9899-1.1349 & 0.095 & & & \\
\hline
\end{tabular}

All other abbreviations as in Tables 1 and 2

$O R$ odds ratio, $\mathrm{Cl}$ confidential interval

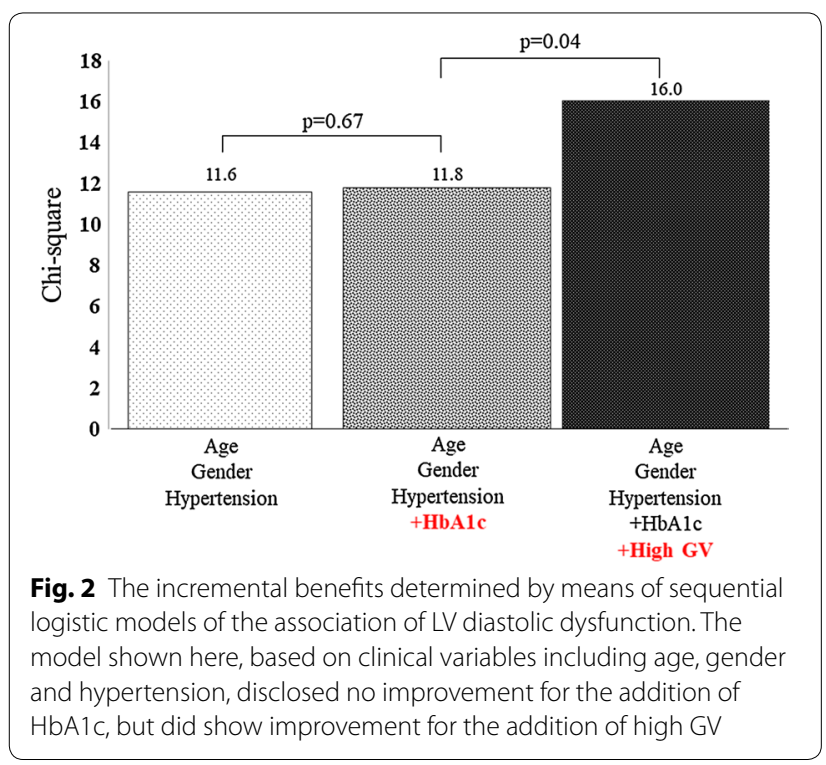

inflammation and endothelial dysfunction resulting in atherosclerosis [23]. Previous research has also suggested that GV plays an important role in the development of complications related to impaired glucose metabolism.

As described previously, both HF and DM closely influence each other, with DM in particular being a major cause of HFpEF, which usually presents as LV diastolic dysfunction. However, the impact of GV on LV function, especially LV diastolic function in asymptomatic T2DM patients with preserved LVEF, remains unclear. However, LV diastolic dysfunction caused by DM-related cardiac abnormality is identifiable as the earliest functional alteration in the course of T2DM patients [24-26], while T2DM is known as a significant factor associated with HFpEF as well as hypertension or obesity. This accounts for the fact that LV diastolic dysfunction is the classical and most frequently observed early LV functional abnormality in T2DM patients [27], and asymptomatic LV diastolic dysfunction has been detected in up to $75 \%$ of normotensive T2DM patients without evident coronary artery disease [28]. For the asymptomatic T2DM patients with preserved LVEF in our study, LV diastolic function of the high GV group was significantly worse than that of the low GV group, while high GV was independently associated with LV diastolic dysfunction. Although the mechanism for the association of GV with LV diastolic function is not yet fully understood, preliminary studies suggest glycemic fluctuations play a role in promoting endothelial toxicity, oxidative stress, and ischemia [22, 29, 30]. Furthermore, it has been reported that rapid glucose swings are also associated with more profound endothelial toxicity than are tonic glucose elevations in vitro [29]. Thus, the main importance of these findings may lie in the potential application of interventions that target glycemic variability.

Moreover, it is recently reported that sitagliptin, a dipeptidyl peptidase-4 (DPP-4) inhibitor-enhanced glucagon-like peptide-1 may ameliorate LV diastolic dysfunction in T2DM by shifting fatty acid to glucose utilization in the cardiomyocyte, and thus, improving cardiac efficiency and reducing lipolysis [31-33]. Therefore, DPP-4 inhibitor might be one of the therapeutic options for the prevention of the future development of HFpEF in T2DM patients. 

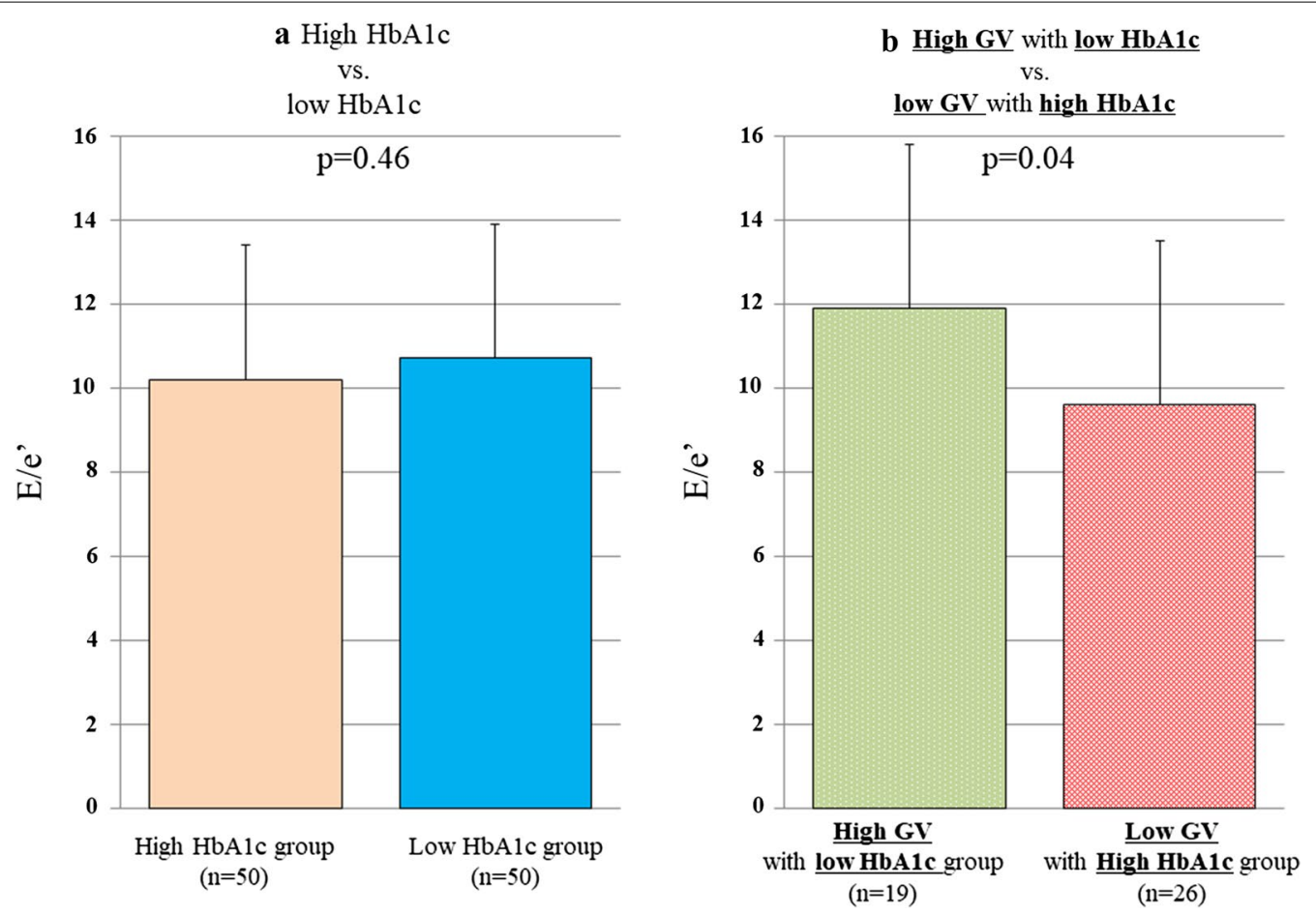

Fig. 3 a Bar graphs of E/e'for the high and low HbAlc groups, showing similar E/e'for both groups. b Bar graphs of E/e'for the high GV group with low HbA1c, and for the low GV group with high $\mathrm{HbA1c}$, showing E/e' for the high GV with low HbA1c group was significantly higher than that for patients with low $\mathrm{GV}$ in the high $\mathrm{HbA} 1 \mathrm{c}$ group

\section{Clinical implication}

As already mentioned the pathogenesis of DM-related cardiac dysfunction is thought to be multifactorial, and possibly a key factor in the development of HFpEF in T2DM patients, which presents as LV diastolic dysfunction. It has also been previously reported that simple suboptimal glycemic control, such as seen in high HbA1c, was associated with the development of HF in patients with newly diagnosed DM, while a $1 \%$ reduction in HbA1c was associated with a $16 \%$ risk reduction in the development of HF in patients with newly diagnosed T2DM [34]. Since there is no effective pharmacological therapy for patients with HFpEF, GV may be another possible therapeutic target for preventing the future development of HFpEF as well as for simple glycemic control in asymptomatic T2DM patients with preserved LVEF without coronary artery disease. Interestingly, LV diastolic function even in patients with high GV and low HbAlc was found to be significantly worse than that in patients with low GV but high HbA1c. A subject for future studies can thus be to determine what kind of antihyperglycemic drugs should be used for the improvement of GV in T2DM patients.

\section{Study limitations}

This study covered a small number of patients, so that further prospective studies with larger patient populations will be needed to validate our findings. The most common parameter of GV is the mean amplitude of glycemic excursion (MAGE), which has been determined by calculating the arithmetic mean of the difference between consecutive peaks and nadir if the difference is $>1 \mathrm{SD}$ of the mean glucose level [35]. Since calculating MAGE for all patients was not possible due to this being a retrospective study, GV was evaluated as SD of blood glucose levels. Finally, only a small number of patients were available for follow-up data after therapeutic intervention for T2DM, so that the effect of therapeutic intervention for GV on LV diastolic function remains unclear.

\section{Conclusion}

GV appears to be an important associated factor for LV diastolic function in asymptomatic T2DM patients with preserved LVEF without coronary artery disease. Since HFpEF is a complex clinical syndrome, reducing GV may represent a new therapeutic strategy for the prevention of the future development of HFpEF in such patients. 


\section{Acknowledgements}

The authors are grateful for the support of the entire staff of the Division of Cardiovascular Medicine, Department of Internal Medicine, Kobe University Graduate School of Medicine Kobe Japan.

\section{Authors' contributions}

SY designed the study, carried out subject recruitment, performed echocardiography, analysed the data, and wrote the manuscript. YM, FS, KY, YT, YS, MS, $\mathrm{KS}, \mathrm{JM}, \mathrm{MS}, \mathrm{HT}, \mathrm{KM}, \mathrm{YH}$, and WO assisted recruitment and manuscript revision $\mathrm{HT}$ and $\mathrm{HK}$ assisted in study design, data interpretation and manuscript revision. All authors read and approved the final manuscript.

\section{Funding}

The authors declare that they have no funding.

\section{Availability of data and materials}

Data sharing not applicable to this article as no datasets were generated or analyzed during the current study.

\section{Ethics approval and consent to participate}

This study was approved by the local ethics committee of Kobe University Hospital (No. 180332).

\section{Consent for publication}

The consent to publish was obtained from all participants in this study.

\section{Competing interests}

The authors declare that they have no competing interests.

\section{Author details}

${ }^{1}$ Division of Cardiovascular Medicine, Department of Internal Medicine, Kobe University Graduate School of Medicine, 7-5-2, Kusunoki-cho, Chuo-ku, Kobe 650-0017, Japan. ${ }^{2}$ Division of Diabetes and Endocrinology, Department of Internal Medicine, Kobe University Graduate School of Medicine, Kobe, Japan.

Received: 23 October 2019 Accepted: 23 November 2019

Published online: 05 December 2019

\section{References}

1. Vazquez-Benitez G, Desai JR, Xu S, Goodrich GK, Schroeder EB, Nichols GA, Segal J, Butler MG, Karter AJ, Steiner JF, et al. Preventable major cardiovascular events associated with uncontrolled glucose, blood pressure, and lipids and active smoking in adults with diabetes with and without cardiovascular disease: a contemporary analysis. Diabetes Care. 2015:38(5):905-12.

2. Kannel WB, McGee DL. Diabetes and cardiovascular disease. The Framingham study. JAMA. 1979;241(19):2035-8.

3. Ponikowski P, Voors AA, Anker SD, Bueno H, Cleland JG, Coats AJ, Falk V, Gonzalez-Juanatey JR, Harjola VP, Jankowska EA, et al. 2016 ESC Guidelines for the diagnosis and treatment of acute and chronic heart failure: The Task Force for the diagnosis and treatment of acute and chronic heart failure of the European Society of Cardiology (ESC) Developed with the special contribution of the Heart Failure Association (HFA) of the ESC. Eur J Heart Fail. 2016;18(8):891-975.

4. MacDonald MR, Petrie MC, Varyani F, Ostergren J, Michelson EL, Young JB, Solomon SD, Granger CB, Swedberg K, Yusuf S, et al. Impact of diabetes on outcomes in patients with low and preserved ejection fraction heart failure: an analysis of the Candesartan in Heart failure: assessment of Reduction in Mortality and morbidity (CHARM) programme. Eur Heart J. 2008:29(11):1377-85.

5. Iribarren C, Karter AJ, Go AS, Ferrara A, Liu JY, Sidney S, Selby JV. Glycemic control and heart failure among adult patients with diabetes. Circulation. 2001;103(22):2668-73.

6. Thrainsdottir IS, Aspelund T, Thorgeirsson G, Gudnason V, Hardarson T, Malmberg K, Sigurdsson G, Ryden L. The association between glucose abnormalities and heart failure in the population-based Reykjavik study. Diabetes Care. 2005:28(3):612-6.
7. Andersen OS, Smiseth OA, Dokainish H, Abudiab MM, Schutt RC, Kumar A, Sato K, Harb S, Gude E, Remme EW, et al. Estimating left ventricular filling pressure by echocardiography. J Am Coll Cardiol. 2017;69(15):1937-48

8. Tanaka $\mathrm{H}$. Utility of strain imaging in conjunction with heart failure stage classification for heart failure patient management. J Echocardiogr. 2019;17(1):17-24.

9. Wang X, Zhao X, Dorje T, Yan H, Qian J, Ge J. Glycemic variability predicts cardiovascular complications in acute myocardial infarction patients with type 2 diabetes mellitus. Int J Cardiol. 2014;172(2):498-500.

10. Picconi F, Di Flaviani A, Malandrucco I, Giordani I, Frontoni S. Impact of glycemic variability on cardiovascular outcomes beyond glycated hemoglobin. Evidence and clinical perspectives. Nutr Metab Cardiovasc Dis. 2012;22(9):691-6.

11. Alberti KG, Zimmet PZ. Definition, diagnosis and classification of diabetes mellitus and its complications. Part 1: diagnosis and classification of diabetes mellitus provisional report of a WHO consultation. Diabet Med. 1998;15(7):539-53.

12. Lang RM, Badano LP, Mor-Avi V, Afilalo J, Armstrong A, Ernande L, Flachskampf FA, Foster E, Goldstein SA, Kuznetsova T, et al. Recommendations for cardiac chamber quantification by echocardiography in adults: an update from the American Society of Echocardiography and the European association of cardiovascular imaging. J Am Soc Echocardiogr. 2015:28(1):1-39.

13. Nagueh SF, Smiseth OA, Appleton CP, Byrd BF 3rd, Dokainish H, Edvardsen T, Flachskampf FA, Gillebert TC, Klein AL, Lancellotti P, et al. Recommendations for the Evaluation of Left Ventricular Diastolic Function by Echocardiography: an Update from the American Society of Echocardiography and the European Association of Cardiovascular Imaging. J Am Soc Echocardiogr. 2016;29(4):277-314.

14. Hozawa H, Sakuma M, Nakagawa M, Ishigaki H, Komaki K, Yamamoto Y, Ikeda J, Kagaya Y, Watanabe J, Shirato K. Post-endsystolic active shortening in the non-ischemic region impairs left ventricular pressure fall in acute ischemic heart. Tohoku J Exp Med. 2002;198(2):107-18.

15. Boudina S, Abel ED. Diabetic cardiomyopathy revisited. Circulation. 2007;115(25):3213-23.

16. Gerstein HC, Swedberg K, Carlsson J, McMurray JJ, Michelson EL, Olofsson B, Pfeffer MA, Yusuf S, Investigators CP. The hemoglobin A1c level as a progressive risk factor for cardiovascular death, hospitalization for heart failure, or death in patients with chronic heart failure: an analysis of the Candesartan in Heart failure: assessment of Reduction in Mortality and Morbidity (CHARM) program. Arch Intern Med. 2008:168(15):1699-704.

17. Romero SP, Garcia-Egido A, Escobar MA, Andrey JL, Corzo R, Perez V, Garcia-Domiguez GJ, Gomez F. Impact of new-onset diabetes mellitus and glycemic control on the prognosis of heart failure patients: a propensitymatched study in the community. Int J Cardiol. 2013;167(4):1206-16.

18. Tomova GS, Nimbal V, Horwich TB. Relation between hemoglobin a(1c) and outcomes in heart failure patients with and without diabetes mellitus. Am J Cardiol. 2012;109(12):1767-73.

19. Eshaghian S, Horwich TB, Fonarow GC. An unexpected inverse relationship between $\mathrm{HbA} 1 \mathrm{c}$ levels and mortality in patients with diabetes and advanced systolic heart failure. Am Heart J. 2006;151(1):91.

20. Hu Y, Liu W, Huang R, Zhang X. Postchallenge plasma glucose excursions, carotid intima-media thickness, and risk factors for atherosclerosis in Chinese population with type 2 diabetes. Atherosclerosis. 2010;210(1):302-6.

21. Mo Y, Zhou J, Li M, Wang Y, Bao Y, Ma X, Li D, Lu W, Hu C, Li M, et al. Glycemic variability is associated with subclinical atherosclerosis in Chinese type 2 diabetic patients. Cardiovasc Diabetol. 2013;12:15.

22. Monnier L, Mas E, Ginet C, Michel F, Villon L, Cristol JP, Colette C. Activation of oxidative stress by acute glucose fluctuations compared with sustained chronic hyperglycemia in patients with type 2 diabetes. JAMA. 2006;295(14):1681-7.

23. Rizzo MR, Barbieri M, Marfella R, Paolisso G. Reduction of oxidative stress and inflammation by blunting daily acute glucose fluctuations in patients with type 2 diabetes: role of dipeptidyl peptidase-IV inhibition. Diabetes Care. 2012;35(10):2076-82.

24. Galderisi M. Diastolic dysfunction and diabetic cardiomyopathy: evaluation by Doppler echocardiography. J Am Coll Cardiol. 2006;48(8):1548-51.

25. From AM, Scott CG, Chen HH. The development of heart failure in patients with diabetes mellitus and pre-clinical diastolic dysfunction a population-based study. J Am Coll Cardiol. 2010;55(4):300-5. 
26. Poirier P, Bogaty P, Garneau C, Marois L, Dumesnil JG. Diastolic dysfunction in normotensive men with well-controlled type 2 diabetes: importance of maneuvers in echocardiographic screening for preclinical diabetic cardiomyopathy. Diabetes Care. 2001;24(1):5-10.

27. Fang ZY, Prins JB, Marwick TH. Diabetic cardiomyopathy: evidence, mechanisms, and therapeutic implications. Endocr Rev. 2004;25(4):543-67.

28. Boyer JK, Thanigaraj S, Schechtman KB, Perez JE. Prevalence of ventricular diastolic dysfunction in asymptomatic, normotensive patients with diabetes mellitus. Am J Cardiol. 2004:93(7):870-5.

29. Quagliaro L, Piconi L, Assaloni R, Martinelli L, Motz E, Ceriello A. Intermittent high glucose enhances apoptosis related to oxidative stress in human umbilical vein endothelial cells: the role of protein kinase $C$ and NAD(P)H-oxidase activation. Diabetes. 2003:52(11):2795-804.

30. Desouza C, Salazar H, Cheong B, Murgo J, Fonseca V. Association of hypoglycemia and cardiac ischemia: a study based on continuous monitoring. Diabetes Care. 2003;26(5):1485-9.

31. Ramirez E, Picatoste B, Gonzalez-Bris A, Oteo M, Cruz F, Caro-Vadillo A, Egido J, Tunon J, Morcillo MA, Lorenzo O. Sitagliptin improved glucose assimilation in detriment of fatty-acid utilization in experimental type-II diabetes: role of GLP-1 isoforms in Glut4 receptor trafficking. Cardiovasc Diabetol. 2018;17(1):12.
32. Qiao S, Mao G, Li H, Ma Z, Hong L, Zhang H, Wang C, An J. DPP-4 Inhibitor Sitagliptin improves cardiac function and glucose homeostasis and ameliorates beta-cell dysfunction together with reducing S6K1 activation and IRS-1 and IRS-2 degradation in obesity female mice. J Diabetes Res. 2018:2018:3641516.

33. Scheen AJ. The safety of gliptins: updated data in 2018. Expert Opin Drug Saf. 2018;17(4):387-405

34. Stratton IM, Adler Al, Neil HA, Matthews DR, Manley SE, Cull CA, Hadden D, Turner RC, Holman RR. Association of glycaemia with macrovascular and microvascular complications of type 2 diabetes (UKPDS 35): prospective observational study. BMJ. 2000;321(7258):405-12.

35. Service FJ, Molnar GD, Rosevear JW, Ackerman E, Gatewood LC, Taylor WF. Mean amplitude of glycemic excursions, a measure of diabetic instability. Diabetes. 1970;19(9):644-55.

\section{Publisher's Note}

Springer Nature remains neutral with regard to jurisdictional claims in published maps and institutional affiliations.
Ready to submit your research? Choose BMC and benefit from:

- fast, convenient online submission

- thorough peer review by experienced researchers in your field

- rapid publication on acceptance

- support for research data, including large and complex data types

- gold Open Access which fosters wider collaboration and increased citations

- maximum visibility for your research: over $100 \mathrm{M}$ website views per year

At BMC, research is always in progress.

Learn more biomedcentral.com/submissions 